\title{
Prevalence of Intestinal Parasites amongst selected age groups within Okada, South -South Nigeria.
}

\author{
Okafor-Elenwo, E. J., Izevbuwa, E.O., \& Akpoka, O. A.
}

Department of Biological Science, College of Natural and Applied Sciences, Igbinedion University, Okada, Nigeria.

\section{Abstract}

This study was conducted to determine the prevalence of intestinal parasites from volunteered individuals in the study site. A total of 300 stool samples, comprising 150 females and 150 males were collected randomly from the study population in Ovia North-East Local Government Area in Edo State, aged between 1 and 60 years. The stool samples were aseptically collected and examined using both direct smear method and formol ether sedimentation techniques to determine the individual parasite load of the sampled population. The age group of $16-20$ had the highest number of participants $102(34 \%)$ while the age group of 6-10, 51-55 and 56-60 had the least number of participants of $3(1 \%)$ respectively. Out of the 300 stool samples examined $87,(29 \%)$ were positive with intestinal parasites while $213(71 \%)$ were negative, not having any intestinal parasitic infection However the age group of $11-15(\mathrm{~N}=10)$ and $31-35(\mathrm{~N}=10)$ had the highest prevalence rate of $11.5 \%$, while the lowest prevalence $(1 \%)$ was found in individuals of ages 41-60 years. There was no intestinal parasites found among the individuals below11 years of age.. Of the 150 male candidates examined, 57 (65.5\%) were infected with intestinal parasites. On the other hand, their female counterparts had a total prevalence of $34.5 \%$. A total number of six parasitic species were isolated from the fecal specimens. These were Ascaris lumbricoides, Trichuris trichiura, Strongyloides stercolaris, Entamoeba coli, Hookworms and Entamoeba histolytica. Ascaris lumbricoides had the highest prevalence rate (12\%), while Trichuris trichiura and Strongyloides stercolaris had the least prevalence rate (1\%) respectively. The intestinal parasite infection and age were negatively correlated and there was a significant difference between the male and female infection rates $(p<0.05)$.

\section{Article History}

Received 03 March 2020

Accepted 14 June 2020

\section{Keyword}

Prevalence, Intestinal parasites, Formol ether, Helminthes, Protozoans.

\section{Introduction}

Intestinal parasites are parasites that populate the gastro-intestinal tract, typically protozoa and helminthes which are the two major types of intestinal parasites (Udensi, et al., 2015). There are over 65,000 species of protozoa found in nature existing in various forms of 
symbiotic relationships with man and his domestic animal who becomes victims of the parasites (Udensi, et al., 2015).

Parasitic infections of the gastro-intestinal tract of man are amongst the most common infections globally and it is estimated that about 3.5 billion people are affected with children being more susceptible to the infection due to their vulnerability to nutritional deficiencies (Udensi, et al., 2015; Nxasana, et al., 2013,).

The helminthes $T$. trichiura, Ascaris lumbricoides and the hookworm as well as the protozoa Entamoeba histolytica have been observed to cause infections of varying degrees in 48 million people worldwide (Udensi, et al., 2015; Ekpo, et al., 2008; Elliott, et al., 2007; Alaofe, et al., 2008).

Intestinal parasitic infections are a serious public health problem because they can cause iron deficiency, anaemia, growth retardation in growing adults and children as well as causing varying physical and mental health conditions (Nxasana et al., 2013; Esiet, et al., 2017).

High prevalence of infections associated with intestinal parasites can be attributed to poverty, poor environmental hygiene and inadequacies in medical services (Nxasana et al., 2013; Odo, et al., 2016; Akinbo, et al., 2011; Kwitshana, et al., 2008; Ostan, et al., 2007; Okyay, et al., 2004).

In Nigeria, a considerable amount of human and animal wastes are discharged into the soil daily leading to seepage with pathogenic organisms which includes cysts, eggs and larvae of these parasites (Udensi, et al., 2015).

\section{Materials and Methods}

Sterile Universal Specimen bottles (with screw caps) without preservatives were used to collect stool samples from the participants dung. This study's unique identification numbers were also assigned to the sample bottles matching the biodata of the individual participant provided in a re-filled questionnaire.

All participants were asked to transfer an aliquot of their early morning stool samples into the sterile labelled sample bottles. The samples were then received and transported in cooler bags to the Microbiology laboratory of Igbinedion University, Okada within two hours of sample collection. Properly collected stool samples were then processed using formalin ethyl-acetate concentration technique as described by Nyundo et al., (2017). After concentration, a drop from the sediment was placed onto a sterile, grease-free microscope slide and covered with cover slip. The entire cover slip was examined with 10x Objective and 40x Objective respectively to observe the presence and morphology of eggs, cysts or larvae of intestinal parasites. The results obtained from each sample were recorded in special record sheets.

\section{Results}

The total number of individuals examined was 300 . These were grouped into different age categories with an interval of 5 years, for each class boundary. The highest number of individuals was found in the class boundary of 16- 20 years, with a total number of 102 individuals. The least number of participants ( 3 each) was obtained from the class boundaries of 6-10, 51-55 and 56-60 years respectively. The variation in the number of participants in different age groups was likened to the availability of the individuals at the time of study. 
The sex related distribution of the participants is shown in figure 2 . There were equal number of male and female participants showing a prevalence of $50 \%$ each.

Out of the 300 individuals examined in the various age groups, 87 had intestinal parasites in their stools. Prevalence of the infection is $29 \%$ while the uninfected had a prevalence of $71 \%$.

The age prevalence of the infection is shown in figure 4 . The highest prevalence was obtained from the $16-20$ years and $31-35$ years age categories. This was followed by the $11-$ 15 years category with a total prevalence of $9 \%$.

Out of the 87 infected individuals, the males were 57 representing a prevalence of $65.5 \%$ while the females were comparatively lower both in the number of individuals $(\mathrm{N}=30)$ and the prevalence rate(34.5\%).

The total number of intestinal parasites obtained from the fecal specimens was 87 , out of which, the parasite species were six in number. The prevalence of the individual parasite group showed that $A$. lumbricoides had the highest prevalence rate compared with the other parasitic species. The lowest occurring parasites were T. trichiura and S. stercoralis, fig. 5

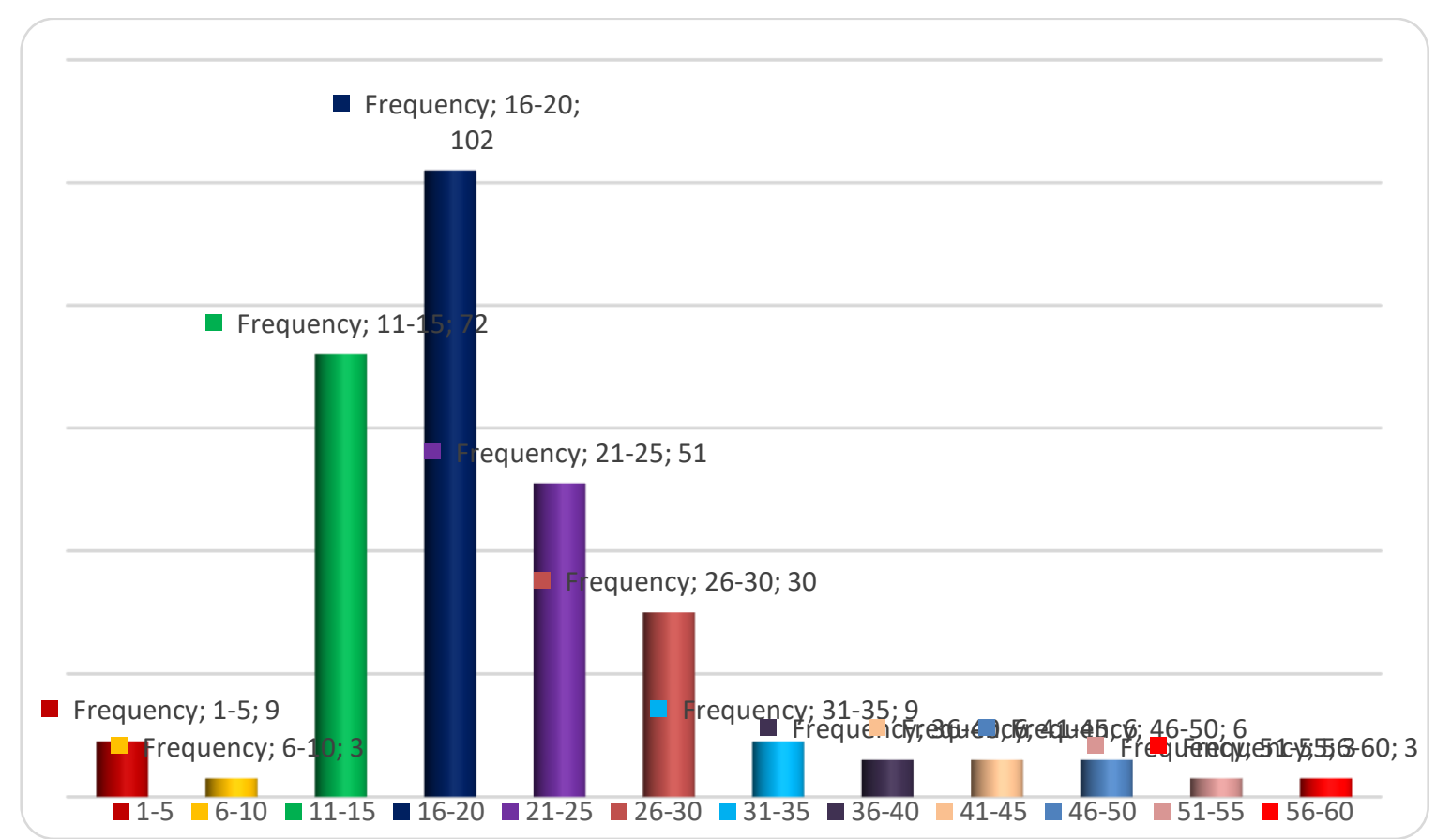

Figure 1 . Age Distribution of the Sulbjects 

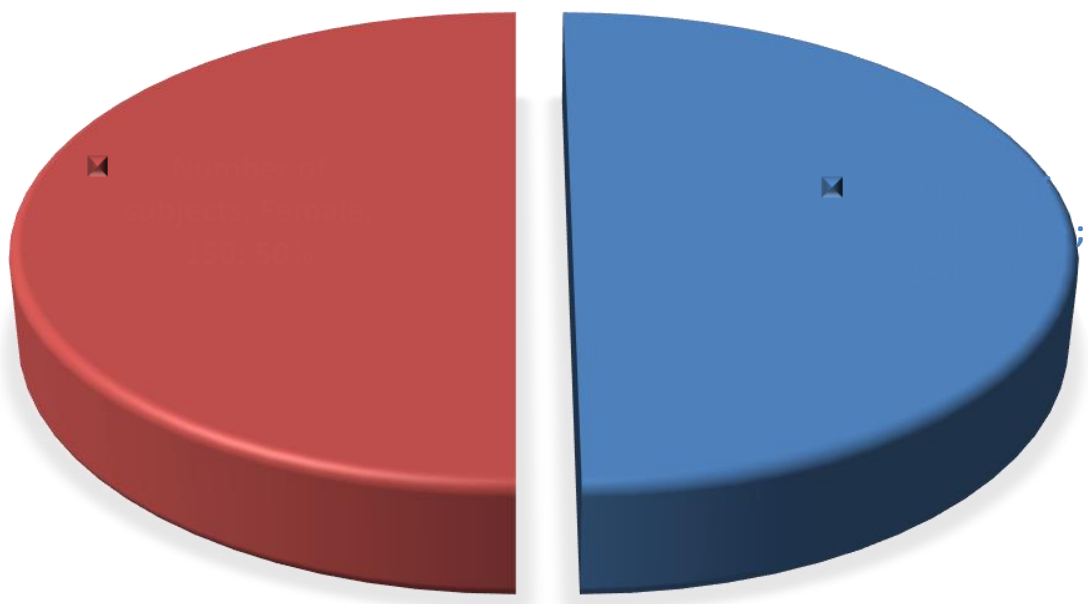

Figure 2. Sex distribution of subjects

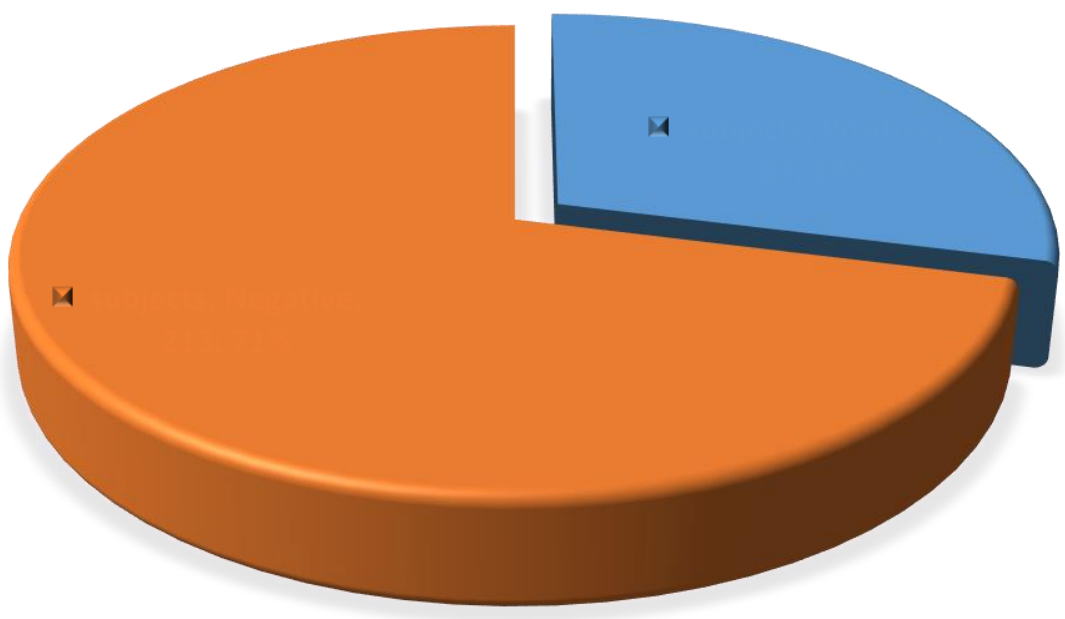

Figure 3. Percentage of Subjects with Intestinal Parasites 


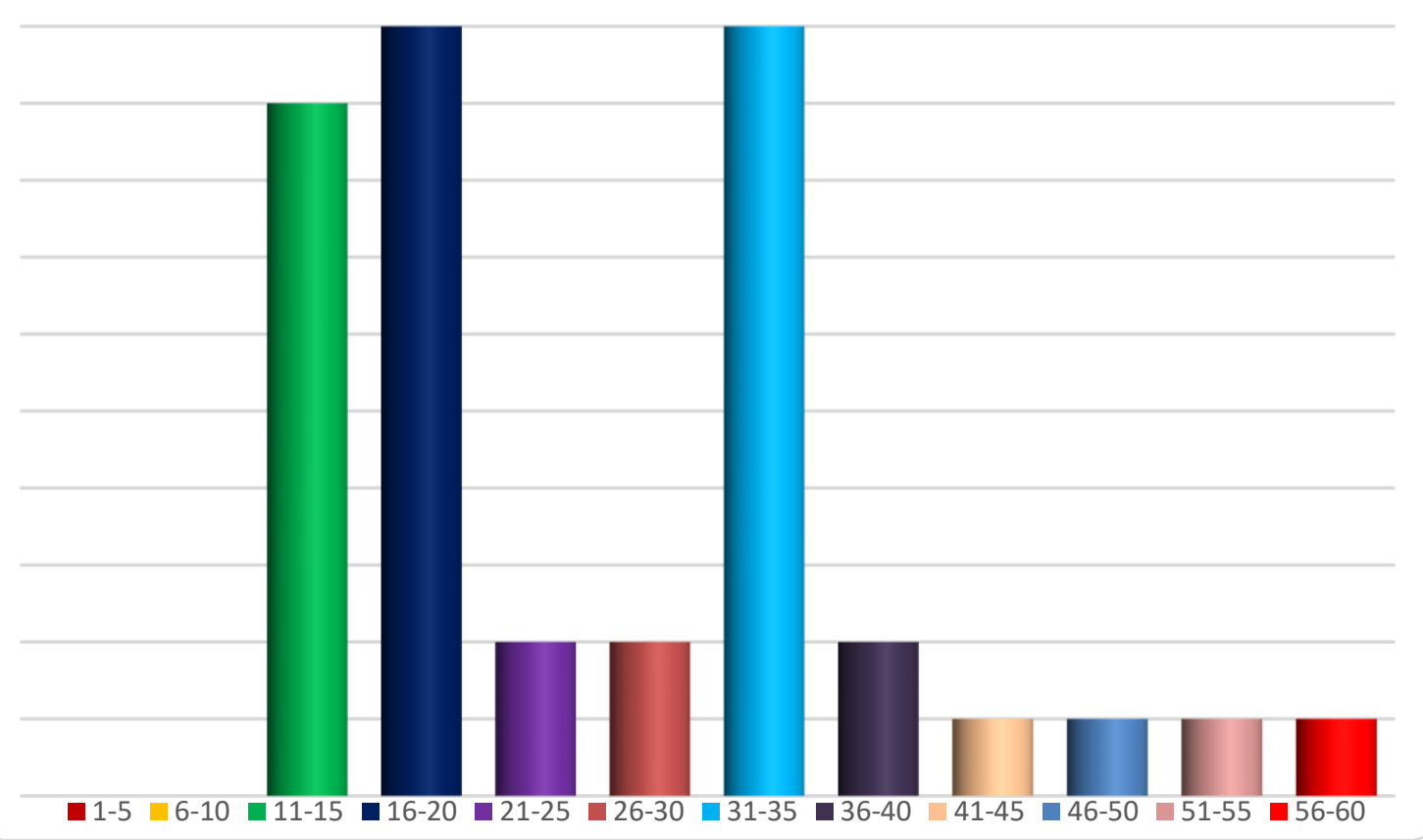

Figure 4. Age related prevalence of Intestinal parasites

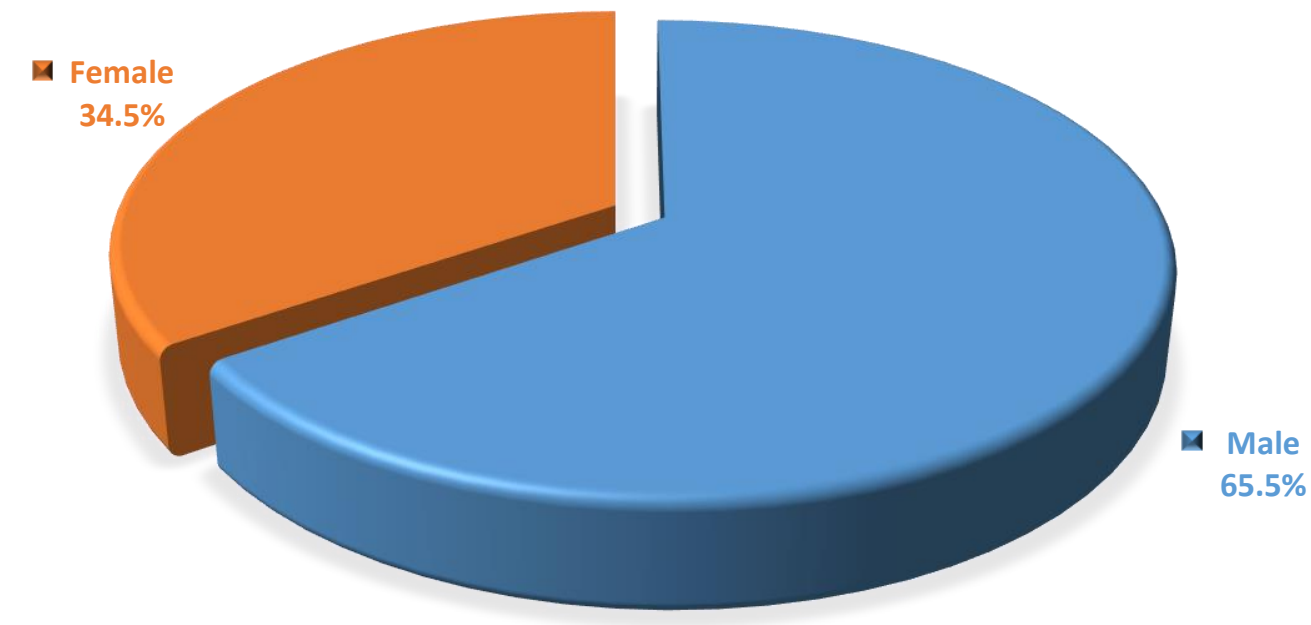

Figure 5. Gender prevalence of positive samples. 


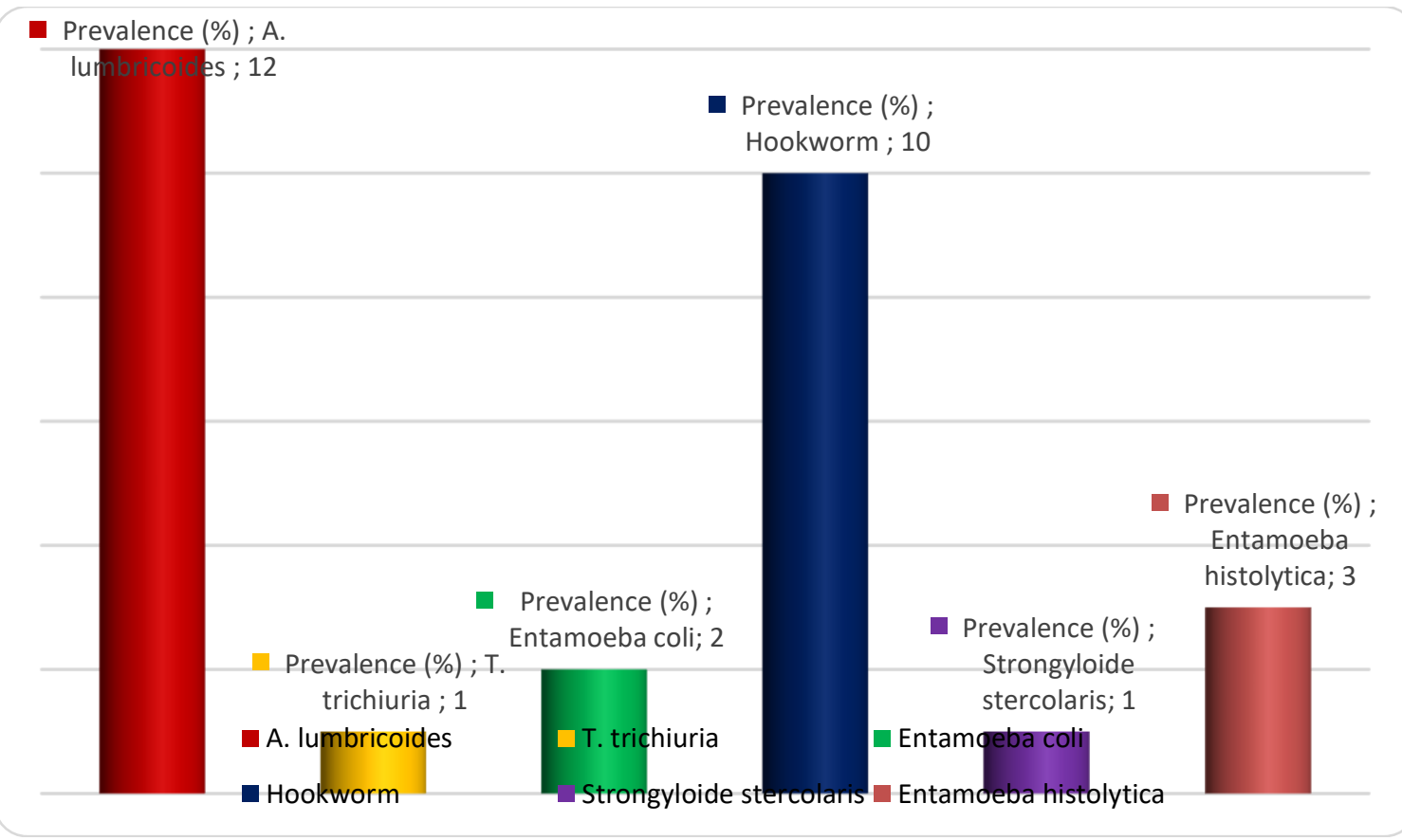

Figure 6. Prevalence of parasites

\section{Discussion}

In this study, the prevalence of $29 \%$ gastro-intestinal parasites was observed amongst in-patients of Igbinedion University Teaching Hospital, Okada, Edo State. This result is similar to the report by Ede, et al., on the prevalence of intestinal parasites among primary school children in Wukari L.G.A of Taraba State, Nigeria. However, in some rural communities in North - Eastern Nigeria, a higher prevalence of $80.9 \%$ was reported amongst Almajiri school children (Damen, et al., 2013). Similar results of (58.5\%) and (51.0\%) were also observed in rural communities in Benue State, Nigeria.

Similar prevalence rate of intestinal parasites of $29.0 \%$ was also recorded among Preschool children in some urban communities in Benue State, Nigeria. The low percentage rate of infection recorded in these studies may be attributed to public enlightenment and sensitization on good environmental and personal hygiene and accessibility to health care facilities.

The presence of six (6) species of intestinal parasites in this study area suggests that the prevailing environmental conditions support a wide range of intestinal parasites. Among the helminthes observed, the most prevalent was Ascaris lumbricoides with $12 \%$ occurrence, followed by Hookworm with $10 \%$. For the protozoan parasites, E. histolytica had the highest prevalence rate of (3\%) while Strongyloides stercoralis and Trichostrongylus spp both had the least prevalence of $1 \%$ each.

These patterns observed are in line with the findings of some researchers in parts of Nigeria (Udensi, et al., 2015; Akinbo, et al., 2011 and Kpurkpur et al., 2016). According to Udensi, et al., 2015, the patterns of intestinal parasites distribution among school age children may be attributed to factors such as poor toilet facilities, children playing in filthy environment, as well as poor supply of portable drinking water.

The age groups of $16-20$ and $31-35$ years had the highest prevalence of $(10 \%)$ which is not in accordance with reports by Akinbo et al., 2011, who recorded higher prevalence of intestinal parasites amongst patients aged 51 years and above. The lower prevalence rate of intestinal parasitic infection among participants aged 41 years and above, as well as children 
aged 1-6 and 6-10 years respectively compared with the participants aged 16-20 and $31-35$ could indicate behavioral patterns observed among families in rural and sub urban settings where the younger ones stay at home and are well catered for, while the older children run most of the errands which includes open water related chores such as fishing, washing and processing of some food products in streams and rivers. The middle aged class is also mostly engaged in agricultural activities and fish farming which constantly expose them to parasites deposited in the soils, water bodies and other reservoirs in their immediate environment.

In this study, it was discovered that more males (65\%) than females (35\%) were infected. This could relate to the fact that males are more outgoing and could be exposed to environmental contaminants than the females who mostly stay at home to attend to most of the domestic chores.

The correlation between age and the infection rate of intestinal parasites in the present study is negative. This observation is in line with the pattern of intestinal parasitic infection in most rural study areas. This agrees with the work of Udensi et al., (2015) who observed similar results in his study.

\section{Conclusions}

From the present study, it was ascertained that the rate of occurrence of intestinal parasitic infection was low probably due to the peri- urban nature of Okada community. The six parasitic species isolated from the fecal specimens were randomly distributed among the various age groups except for the 1-10 age brackets. The prevalence was high among the young adults of ages 11-15, 16-20 and the adult age group of 31-35. The gender prevalence was highest among the males. There was a negative correlation between age and the infection rate. The pattern of infection with intestinal parasites in this study shows that the more active age groups have more parasite loads compared to the others. It is therefore, pertinent to consider this infection pattern while initiating control programs of parasitic infections in rural communities.

\section{References}

Akinbo, F.O., Omoregie, R., Eromowon, R., Igbinedion, I.O, and Airueghiomon, U. (2011). Prevalence of intestinal parasites among patients of a tertiary hospitals in Benin city, Nigeria. North American Journal of Medical Sciences, 3(10): 462-464.

Alaofè, H., Zee, J., Dossa, R., O’Brien, H. T.( 2008). Intestinal Parasitic Infections in Adolescent Girls from two Boarding Schools in Southern Benin. Transactions of the Royal Society of Tropical Medicine and Hygiene, 10(2):653-661.

Damen, J.G., Luka, J., Biwan, E. I. and Lugos, M. (2013). Prevalence of Intestinal Parasites among Pupils in rural North-Eastern Nigeria. Journal of the Nigeria Medical Association, 52(1): 4-6.

Elliott, A. M., Kizza, M., Quigley, M. A., Ndibazza, J., Nampijja, M., Muhangi, L. (2007).The Impact of Helminths on the Response to Immunization and on the Incidence of Infection and Disease in Childhood in Uganda: Design of a Randomized, Double-Blind, Placebo-Controlled, Factorial Trial of Deworming Interventions Delivered in Pregnancy and Early Childhood. Clinical Trials, 4(1):42-57. 
Ekpo, U. F., Odoemene, S. N., Mafiana, C. F., Sam-Wobo, S. O.( 2008). Helminthiasis and Hygiene Conditions of Schools in Ikenne, Ogun State, Nigeria. PLOS Neglected Tropical Diseases, 2(1): 146.

Esiet, U.P. and Edet, I.A. (2017). Comparative Relevance of intestinal parasites among children in public and private schools in calabar south , Cross River state, Nigeria. American Journal of Research communication, 5(1): 80- 97.

Kpurkpur, T, Sani, A. and Nongu, C. (2016). Prevalence of Intestinal Parasitic Infection and their Association with Nutritional Status of Rural and Urban Pre-School Children in Benue State, Nigeria. International Journal of Maternal and Child Health and AIDS. 5(2):146-152.

Kwitshana, Z. L., Tsoka, J. M., Mabaso, M. L. (2008). Intestinal Parasitic Infections in Adult Patients in KwaZulu-Natal. South African Medical Journal, 98(9):709-711.

Nxasana, N., Babak, Bhat, V.G. and Vasaikar, S.D. (2013). Prevalence of intestinal parasites in primary school children of mthatha, Eastern cape province, South Africa. Annals of medical and health sciences Research, 3(4): 511-516.

Nyundo, A. A., Munisi, D. Z. and Gesase, A. P. (2017). Prevalence and Correlates of Intestinal Parasites among Patients Admitted to Mirembe National Mental Health hospital Dodoma, Tanzania. Journal of Parasitology Research, (2017): 6.

Okyay, P., Ertug, S., Gultekin, B., Onen, O., Beser, E. (2004). Intestinal parasites prevalence and related factors in school children, a western city sample - Turkey. BMC Public Health. 4(64): 1-6

Ostan, I., Kilimcioğlu, A. A., Girginkardeşler, N., Ozyurt, B. C., Limoncu, M. E., Ok, U.Z. ( 2007). Health Inequities: Lower Socio-Economic Conditions and Higher Incidences of Intestinal Parasites. BMC Public Health, 7(3):42.

Udensi, J.U., Mgbemene, I.C., Emeka-Nwabunnia, I., Ugochukwu, M.G. and Awurum, I.N. (2015). Prevalence of intestinal parasites among primary school children in three geopolitical zones of imo state, Nigeria. Science Journal of public health, 5(3): 25- 28 